\title{
Natural history of grade 1 ascites in patients with liver cirrhosis
}

\author{
Theodoros Theodorakopoulos a , Maria Kalafatelia, Georgios N. Kalambokis ${ }^{b}$, Dimitrios N. Samonakisc, \\ Ioanna Aggeletopouloua, Chrysostomos Tsolias a, Aikaterini Mantakac, Paraskevi Tselekounia, \\ Georgia Vourlid, Stelios F. Assimakopoulos ${ }^{\mathrm{e}}$, Charalampos Gogos ${ }^{\mathrm{e}}$, Konstantinos Thomopoulos ${ }^{\mathrm{a}}$, \\ Haralampos Milionis ${ }^{b}$, Christos Triantos ${ }^{a}$
}

University Hospital of Patras; Medical School, University of Ioannina; University Hospital of Crete; Medical School, University of Athens, Greece

\section{Abstract}

\begin{abstract}
Background No evidence is available on the natural history of grade 1 ascites and its progression to grade $2 / 3$ in patients with liver cirrhosis. The aim of the current study was to address this issue, to assess the development of main comorbid disorders closely related to ascites progression, and to identify the predictive factors for survival in this setting.
\end{abstract}

Methods Consecutive Caucasian cirrhotic patients with grade 1 ascites were retrospectively analyzed. None of patients was under treatment with diuretics at diagnosis. Control groups consisted of 145 cirrhotics with grade $2 / 3$ ascites and 175 cirrhotics without ascites.

Results Diuretics were initiated in 58 patients with grade 1 ascites at baseline by the attending physician. At the last follow up, 29 patients had no ascites, 33 patients had grade 1 and 38 patients had grade $2 / 3$ ascites. No variable was found to be an independent predictor of grade $2 / 3$ ascites. Seven patients developed spontaneous bacterial peritonitis while under treatment with diuretics; at that time only 1 patient had grade 1 ascites. The mortality rate was similar among all examined groups.

Conclusions This study suggests that the presence of grade 1 ascites does not constitute a precursor of grade $2 / 3$ ascites in patients with cirrhosis. Thus, patients with grade 1 ascites do not require specific treatment with diuretics.

Keywords Ascites, grade 1, natural history, liver cirrhosis

Ann Gastroenterol 2021; 34 (1): 1-16

\section{Introduction}

The presence of ascites is considered to be a significant landmark in liver cirrhosis, as it is associated with

Division of a Gastroenterology, Department of Internal Medicine, University Hospital of Patras (Theodoros Theodorakopoulos, Maria Kalafateli, Ioanna Aggeletopoulou, Chrysostomos Tsolias, Paraskevi Tselekouni, Konstantinos Thomopoulos, Christos Triantos); ' Internal Medicine, First Division of Internal Medicine and Liver Unit, Medical School, University of Ioannina, Ioannina (Georgios N. Kalambokis, Haralampos Milionis); ' Gastroenterology and Hepatology, University Hospital of Crete, Heraklion, Crete (Dimitrios N. Samonakis, Aikaterini Mantaka); ${ }^{\mathrm{d} H y g i e n e, ~ E p i d e m i o l o g y ~ a n d ~ M e d i c a l ~ S t a t i s t i c s, ~}$ Medical School, University of Athens (Georgia Vourli); ${ }^{\text {eInternal }}$ Medicine, University Hospital of Patras (Stelios F. Assimakopoulos, Charalampos Gogos), Greece

\section{Conflict of Interest: None}

Correspondence to: Christos Triantos, MD, FAASLD,

D. Stamatopoulou 4, Rio 26504, Patras, Greece,

e-mail: chtriantos@hotmail.com

Received 15 May 2020; accepted 2 September 2020; published online 20 November 2020

DOI: https://doi.org/10.20524/aog.2020.0553 decompensation and $50 \%$ mortality over 2 years [1,2]. In addition, the evolution of ascites is connected to a poor quality of life, higher risk of infection, and renal failure [3,4]. The classification of ascites is based on the amount of fluid in the abdominal cavity: grade 1 ascites, or mild ascites, detectable by ultrasound examination; grade 2 ascites, or moderate ascites, characterized by a mild symmetrical abdominal distension; and grade 3 ascites, or large ascites, with significant abdominal distension $[5,6]$. Cirrhotic patients with ascites are at high risk of developing various complications of liver disease, including spontaneous bacterial peritonitis (SBP) and hepatorenal syndrome (HRS) [5,7]. It has been shown that the 1-year probability of survival in patients with uncomplicated ascites is $85 \%$, compared to $25.6 \%, 31.6 \%$ and $38.5 \%$, in patients with hyponatremia, refractory ascites and HRS, respectively [8].

The International Club of Ascites has documented that patients with ascites grade 1 do not require specific treatment, but should be followed-up carefully and advised to reduce their sodium intake, since they usually progress to the development of grade 2 ascites [5]. European Association for the Study of the Liver (EASL) guidelines have reported that there is no data on the evolution of grade 1 ascites, nor it is known whether its 
treatment modifies its natural history [6]. Furthermore, there are no data on how frequently patients with grade 1 develop grade $2 / 3$ ascites $[6,9]$. Therefore, there is a great need for a better understanding of the natural history of ascites grade 1 in liver cirrhosis.

To this end, the current study aimed to assess grade 1 ascites as a representative risk factor for the development of grade $2 / 3$ ascites in patients with cirrhosis, to evaluate the main comorbid disorders which come along with ascites progression, and to identify the predictive factors for survival in this setting.

\section{Patients and methods}

\section{Study population}

One hundred consecutive Caucasian patients with grade 1 ascites were enrolled in this retrospective study. One hundred forty-five consecutive Caucasian patients with grade $2 / 3$ ascites and 175 without ascites served as control groups. The study population was composed of hospitalized medical patients or outpatients from 3 university hospitals in Greece (University Hospital of Patras, $n=315$; University Hospital of Ioannina, $\mathrm{n}=59$; and University Hospital of Heraklion, $\mathrm{n}=46$ ). The recruitment of the patients was performed between November 1993 and July 2014. Blood samples were collected from patients throughout the year.

\section{Definitions}

The diagnosis of liver cirrhosis was based on clinical, laboratory, histological and ultrasonographic findings [10,11]. The severity of liver cirrhosis was assessed by the Child-Pugh (CP) score, CP stage, and by model for end-stage liver disease (MELD) score [12]. The evaluation of ascites was based on medical history, physical examination, abdominal ultrasound, assessment of laboratory parameters and analysis of the ascitic fluid [6]. The diagnosis of SBP was defined as suggested by the International Club of Ascites diagnostic criteria, hepatic encephalopathy (HE) was defined as suggested by the EASL and the American Association for the Study of Liver Diseases practice guidelines, and HRS was defined as suggested by the revised consensus recommendations of the International Club of Ascites [5,13-15]. Patients with human immunodeficiency virus infection and severe cardiopulmonary disease or renal failure were excluded from enrolment. Alcoholic patients ceased alcohol abuse according to the guidelines [16]. Sodium intake restriction was applied, according to guidelines [9] and the physician's intuitive judgment.

\section{Follow up}

The study population was followed-up over a mean period of $18.93 \pm 30.74$ (range: 1-241) months until death or liver transplantation. Diagnostic and therapeutic criteria were applied uniformly during the follow-up period. Patients underwent clinical evaluation in the hepatology clinic at regular intervals according to current guidelines [10]. The initiation of diuretics during follow up in patients with ascites grade 1 was based on the physician's intuitive judgment.

\section{Statistical analysis}

All patients' characteristics were presented separately by ascites status (no ascites, ascites grade 1, ascites grade 2/3) and were compared using chi-square test for categorical characteristics, or the Kruskal-Wallis test for continuous characteristics. Both univariate and multivariate Cox models were used to evaluate potential risk factors for patients' survival. This analysis was repeated in the subgroup of patients with ascites grade 1 . Univariate and multivariate logistic regression models were used for binary outcomes. Life-table analysis with the Kaplan-Meier method was used to estimate proportional outcomes. All comparisons were performed at the 5\% level of significance. Analysis was conducted using Stata (StataCorp, College Station, Texas) version 13.1.

\section{Ethical guidelines}

The study protocol was reviewed and approved by the Ethics Committee of the University Hospital of Patras. The study protocol conformed to the ethical guidelines of the 1975 Declaration of Helsinki for medical research involving human subjects.

\section{Results}

The patients' baseline demographic, clinical and laboratory characteristics are summarized in Table 1. Patients with grade 1 ascites presented at baseline with CP stage A $18 \%$, CP stage B $60 \%$ and CP stage C 22\%; patients with grade $2 / 3$ ascites presented with CP stage A $12.9 \%$, CP stage B $65.2 \%$ and CP stage C 22\%; and lastly, patients with no ascites presented with CP stage A $76 \%$, CP stage B $22.6 \%$ and CP stage C $1.4 \%$. The median MELD score at baseline was 12.5 for those patients with grade 1 ascites, 14.0 for those with grade $2 / 3$ ascites and 9.0 for those with no ascites. At baseline, infection was observed in 6 patients $(6 \%)-\mathrm{SBP}$ in 1 patient (1\%)hepatocellular carcinoma (HCC) in 9 patients (9\%), pleural effusion in 6 patients (6\%), portal gastropathy bleeding in 10 patients $(10 \%)$, acute variceal bleeding in 7 patients $(7 \%)$ and portal vein thrombosis in 5 patients $(5 \%)$ of the grade 1 ascites group. Moreover, at baseline $50(50 \%)$ of the 100 patients with grade 1 ascites had varices ( 23 small and 27 large varices). The development of the main clinical manifestations related to ascites progression in each group of patients during the followup period is presented in Table 2 . 
Table 1 Patients' baseline demographic, clinical and laboratory characteristics

\begin{tabular}{|c|c|c|c|c|c|}
\hline Characteristics & Grade 1 ascites & Grade $2 / 3$ ascites & No ascites & Overall & $\mathrm{P}$-value \\
\hline & $\mathrm{N}(\%)$ & $\mathrm{N}(\%)$ & $\mathrm{N}(\%)$ & $\mathrm{N}(\%)$ & \\
\hline Sex & & & & & 0.004 \\
\hline Male & $88(88.0)$ & $109(75.2)$ & $123(70.3)$ & $320(76.2)$ & \\
\hline Female & $12(12.0)$ & $36(24.8)$ & $52(29.7)$ & $100(23.8)$ & \\
\hline Cause of liver cirrhosis & & & & & $<0.001$ \\
\hline Alcohol & $62(62.0)$ & $105(71.4)$ & $82(47.1)$ & $249(59.2)$ & \\
\hline $\mathrm{HBV}$ & $21(21.0)$ & $25(17.3)$ & $42(24.2)$ & $88(20.9)$ & \\
\hline $\mathrm{HCV}$ & $14(14.0)$ & $8(6.0)$ & $28(15.3)$ & $50(11.8)$ & \\
\hline Autoimmune & $2(2.0)$ & $5(3.8)$ & $23(13.4)$ & $30(7.3)$ & \\
\hline NASH & $1(1.0)$ & $2(1.5)$ & $0(0.0)$ & $3(0.8)$ & \\
\hline Smoking & & & & & 0.767 \\
\hline Yes & $57(57.0)$ & $86(59)$ & $97(55.6)$ & $240(57.2)$ & \\
\hline No & $43(43.0)$ & $59(41)$ & $78(44.4)$ & $180(42.8)$ & \\
\hline Nutritional status & & & & & 0.003 \\
\hline Obese & $13(13.0)$ & $11(7.6)$ & $31(17.7)$ & $55(13.1)$ & \\
\hline Normal & $71(71.0)$ & $112(77.2)$ & $135(77.1)$ & $318(75.7)$ & \\
\hline Malnourished & $16(16.0)$ & $22(15.2)$ & $9(5.1)$ & $47(11.2)$ & \\
\hline CP stage & & & & & $<0.001$ \\
\hline A & $18(18.0)$ & $18(12.9)$ & $134(76.0)$ & $170(38.6)$ & \\
\hline B & $60(60.0)$ & $95(65.2)$ & $39(22.6)$ & $194(47.4)$ & \\
\hline $\mathrm{C}$ & $22(22.0)$ & $32(22.0)$ & $2(1.4)$ & $56(14)$ & \\
\hline Intrinsic renal disease & & & & & 0.046 \\
\hline Yes & $3(3.0)$ & $10(6.9)$ & $3(1.7)$ & $16(3.8)$ & \\
\hline No & $97(97.0)$ & $135(93.1)$ & $172(98.3)$ & $403(96.2)$ & \\
\hline Diabetes mellitus & & & & & 0.746 \\
\hline Yes & $18(18.0)$ & $32(22.1)$ & $36(20.6)$ & $86(20.5)$ & \\
\hline No & $82(82.0)$ & $113(77.9)$ & $139(79.4)$ & $334(79.5)$ & \\
\hline Non-HCC malignancy & & & & & 0.024 \\
\hline Yes & $3(3.0)$ & $6(4.1)$ & $18(10.3)$ & $27(6.4)$ & \\
\hline No & $97(97.0)$ & $139(95.9)$ & $157(89.7)$ & $393(93.6)$ & \\
\hline Hepatic encephalopathy & & & & & 0.042 \\
\hline Yes & $9(9.0)$ & $7(4.8)$ & $4(2.3)$ & $20(4.8)$ & \\
\hline \multirow[t]{2}{*}{ No } & $91(91.0)$ & $138(95.2)$ & $171(97.7)$ & $400(95.2)$ & \\
\hline & Median (IQR) & Median (IQR) & Median (IQR) & Median (IQR) & \\
\hline Age (years) & $59.0(50.0-70.0)$ & $59.0(50.0-67.5)$ & $64.0(50.0-71.0)$ & $60.0(50.0-69.0)$ & 0.318 \\
\hline Plt (cells $/ \mu \mathrm{L})$ & $112.0(68.0-167.0)$ & $124.5(95.0-176.0)$ & $131.0(80.0-190.0)$ & $125.0(81.0-180.0)$ & 0.054 \\
\hline PT (sec) & $16.1(14.6-19.4)$ & $15.9(14.2-18.4)$ & $13.7(12.6-15.4)$ & $14.9(13.1-17.0)$ & $<0.001$ \\
\hline INR & $1.3(1.2-1.5)$ & $1.4(1.2-1.5)$ & $1.2(1.0-1.4)$ & $1.3(1.1-1.5)$ & $<0.001$ \\
\hline Bilirubin $(\mathrm{mg} / \mathrm{dL})$ & $2.1(1.3-4.0)$ & $2.1(1.4-3.4)$ & $1.0(0.7-1.8)$ & $1.6(0.9-2.8)$ & $<0.001$ \\
\hline Albumin (g/dL) & $3.1(2.7-3.7)$ & $3.1(2.8-3.6)$ & $3.8(3.3-4.2)$ & $3.4(3.0-3.9)$ & $<0.001$ \\
\hline
\end{tabular}


Table 1 (Continued)

\begin{tabular}{|c|c|c|c|c|c|}
\hline \multirow[t]{2}{*}{ Characteristics } & Grade 1 ascites & Grade $2 / 3$ ascites & No ascites & Overall & P-value \\
\hline & $\mathrm{N}(\%)$ & $\mathrm{N}(\%)$ & $\mathrm{N}(\%)$ & $\mathrm{N}(\%)$ & \\
\hline Urea $(\mathrm{mg} / \mathrm{dL})$ & $31.0(21.0-39.0)$ & $32.0(22.0-43.0)$ & $33.0(24.0-42.0)$ & $32.0(22.0-42.0)$ & 0.543 \\
\hline Creatinine (mg/dL) & $0.9(0.8-1.0)$ & $0.9(0.7-1.1)$ & $0.9(0.8-1.0)$ & $0.9(0.7-1.0)$ & 0.473 \\
\hline Sodium (mmol/L) & $138.0(135.0-140.0)$ & $137.0(134.2-139.0)$ & $139.0(136.4-142.0)$ & $138.0(135.1-140.0)$ & $<0.001$ \\
\hline CP score & $8.0(7.0-9.0)$ & $8.0(7.0-9.0)$ & $5.0(5.0-6.0)$ & $7.0(6.0-9.0)$ & $<0.001$ \\
\hline $\mathrm{CP}$ creatinine score & $8.0(7.0-10.0)$ & $8.0(7.0-10.0)$ & $5.0(5.0-7.0)$ & $7.0(5.0-9.0)$ & $<0.001$ \\
\hline MELD score & $12.5(10.0-17.0)$ & $14.0(11.0-16.0)$ & $9.0(8.0-12.0)$ & $12.0(9.0-15.0)$ & $<0.001$ \\
\hline MELD-Na score & $14.0(11.0-18.0)$ & $16.0(13.0-19.0)$ & $11.0(8.5-14.0)$ & $14.0(10.0-18.0)$ & $<0.001$ \\
\hline
\end{tabular}

$\mathrm{N}$, number of patients; HBV, hepatitis B virus; HCV, hepatitis C virus; $N A S H$, non-alcoholic steatohepatitis, $C P$, Child-Pugh; HCC, hepatocellular carcinoma; Plt, platelets; PT, prothrombin time; INR, international normalized ratio; MELD, model for end-stage liver disease; IQR, interquartile range

Table 2 The development of main clinical manifestations related to ascites progression during follow up

\begin{tabular}{|c|c|c|c|c|c|c|c|}
\hline \multirow[t]{3}{*}{ Characteristics } & \multirow{3}{*}{$\begin{array}{c}\text { Overall } \\
\mathbf{N}(\%)\end{array}$} & \multicolumn{3}{|c|}{ Grade 1 ascites vs. Grade $2 / 3$ ascites } & \multicolumn{3}{|c|}{ Grade 1 ascites vs. No ascites } \\
\hline & & Grade 1 ascites & Grade $2 / 3$ ascites & $\mathrm{P}$-value & Grade 1 ascites & No ascites & P-value \\
\hline & & N (\%) & N (\%) & & N (\%) & N (\%) & \\
\hline Hepatic encephalopathy & & & & 0.742 & & & $<0.001$ \\
\hline No & $351(83.6)$ & $77(77.0)$ & $109(75.2)$ & & $77(77.0)$ & $165(94.3)$ & \\
\hline Yes & $69(16.4)$ & $23(23.0)$ & $36(24.8)$ & & $23(23.0)$ & $10(5.7)$ & \\
\hline Hepatorenal syndrome & & & & 0.481 & & & $<0.001$ \\
\hline No & $398(94.8)$ & $90(90.0)$ & $134(92.4)$ & & $90(90.0)$ & $174(99.4)$ & \\
\hline Yes & $22(5.2)$ & $10(10.0)$ & $11(7.6)$ & & $10(10.0)$ & $1(0.6)$ & \\
\hline HCC & & & & 0.054 & & & 0.287 \\
\hline No & $372(88.6)$ & $93(93.0)$ & $123(84.8)$ & & $93(93.0)$ & $156(89.1)$ & \\
\hline Yes & $48(11.4)$ & $7(7.0)$ & $22(15.2)$ & & $7(7.0)$ & $19(10.9)$ & \\
\hline Pleural effusion & & & & 0.225 & & & $<0.001$ \\
\hline No & $374(89.0)$ & $86(86.0)$ & $117(80.7)$ & & $86(86.0)$ & $171(97.7)$ & \\
\hline Yes & $46(11.0)$ & $14(14.0)$ & $28(19.3)$ & & $14(14.0)$ & $4(2.3)$ & \\
\hline Portal gastropathy bleeding & & & & 0.924 & & & 0.030 \\
\hline No & $382(90.8)$ & $88(88.0)$ & $127(87.5)$ & & $88(88.0)$ & $167(95.4)$ & \\
\hline Yes & $38(9.2)$ & $12(12.0)$ & $18(12.6)$ & & $12(12.0)$ & $8(4.6)$ & \\
\hline New variceal bleeding & & & & 0.030 & & & 0.129 \\
\hline No & $367(87.5)$ & $89(89.0)$ & $113(78.1)$ & & $89(89.0)$ & $165(94.3)$ & \\
\hline Yes & $53(12.5)$ & $11(11.0)$ & $32(31.8)$ & & $11(11.0)$ & $10(5.7)$ & \\
\hline Portal vein thrombosis & & & & 0.304 & & & 0.116 \\
\hline No & $396(94.2)$ & $94(94.0)$ & $131(90.4)$ & & $94(94.0)$ & $171(97.7)$ & \\
\hline Yes & $24(5.7)$ & $6(6.0)$ & $14(9.7)$ & & $6(6.0)$ & $4(2.3)$ & \\
\hline Infection & & & & 0.633 & & & 0.002 \\
\hline No & $310(73.5)$ & $68(68.0)$ & $94(64.8)$ & & $68(68.0)$ & $148(84.5)$ & \\
\hline Yes & $110(26.5)$ & $32(32.0)$ & $51(35.2)$ & & $32(32.0)$ & $27(15.5)$ & \\
\hline
\end{tabular}

$\mathrm{N}$, number of patients; HCC, hepatocellular carcinoma 


\section{Ascites outcome}

At the last follow up, 29 patients (29\%) had no ascites, 33 patients (33\%) had grade 1,17 patients (17\%) had grade 2 and 21 patients (21\%) had grade 3 ascites. A univariate analysis was performed in the grade 1 ascites group to explore the factors associated with ascites outcome (regression, stability or deterioration) at the last follow up. Patients' advanced age $(\mathrm{P}=0.041)$ and HCC $(\mathrm{P}=0.042)$ were the only factors related to ascites outcome. In the multivariate analysis, no variable was found to be an independent predictor of ascites outcome. A separate analysis was conducted for the identification of risk factors for grade $2 / 3$ ascites development. In the univariate analysis, advanced age $(\mathrm{P}=0.012)$ and $\mathrm{HCC}$ $(\mathrm{P}=0.044)$ were found to be potential predictors of grade $2 / 3$ ascites. In the multivariate analysis, no variable was found to be an independent predictor of grade $2 / 3$ ascites.

\section{Diuretics}

Treatment with diuretics was initiated in 58 patients with grade 1 ascites (58\%) at baseline. During follow up, 78 patients with grade 1 (78\%), 89 patients with grade $2 / 3(61 \%)$ and 30 patients with no ascites (17.2\%) were treated with diuretics. Treatment with diuretics at baseline (odds ratio [OR] 0.534, 95\% confidence interval [CI] 0.214-1.336; $\mathrm{P}=0.177$ ) or during follow up (OR 1.887, 95\%CI 0.571-6.229; $\mathrm{P}=0.292$ ) was not correlated with regression of ascites. Twenty-five patients with grade 1 ascites treated with diuretics had regression of ascites, 20 patients had stable ascites and 33 patients had worsening ascites at the last follow up.

\section{HE}

Twenty-three patients with ascites grade 1 (23\%), 36 patients with ascites grade $2 / 3(24.8 \%)$, and 10 patients with no ascites $(5.7 \%)$ presented $\mathrm{HE}$ during follow up $(\mathrm{P}<0.001)$. The univariate analysis of factors correlated with HE development is presented in Supplementary Table 1. Multivariate analyses were performed between 2 sets of variables for the total population to avoid collinearity errors (Table 3 ). The use of diuretics, $\mathrm{HE}$ at baseline and international normalized ratio in the first analysis, and the use of $\beta$-blockers, diuretics, and $\mathrm{CP}$ stage $\mathrm{B}$ and $\mathrm{C}$ in the second, were independently associated with HE development. The same analyses were conducted in the group of patients with ascites grade 1 (Supplementary Table 2); in the multivariate analysis no variable was found to be independently associated with HE development.

\section{HRS}

Ten patients with ascites grade $1(10 \%), 11$ patients with ascites grade $2 / 3(7.6 \%)$ and 1 patient with no ascites $(0.6 \%)$ developed HRS during follow up $(\mathrm{P}=0.001)$. Fourteen patients with HRS (63.6\%) had developed concomitant SBP infection. The factors
Table 3 Multivariate analyses of factors correlating with the main comorbid disorders that accompany ascites progression in the total population

Hepatic encephalopathy development

MODEL 1

\begin{tabular}{|c|c|c|}
\hline Parameters & OR $(95 \% \mathrm{CI})$ & P-value \\
\hline \multicolumn{3}{|l|}{ Group } \\
\hline No ascites ${ }^{*}$ & 1 & \\
\hline Grade 1 ascites & $2.12(0.86-5.24)$ & 0.102 \\
\hline Grade 2-3 ascites & $2.27(0.96-5.40)$ & 0.064 \\
\hline \multicolumn{3}{|l|}{$\beta$-blockers } \\
\hline $\mathrm{No}^{*}$ & 1 & \\
\hline Yes & $1.87(0.96-3.64)$ & 0.067 \\
\hline \multicolumn{3}{|l|}{ Diuretics } \\
\hline $\mathrm{No}^{*}$ & 1 & \\
\hline Yes & $4.05(1.36 .13 .03)$ & 0.019 \\
\hline \multicolumn{3}{|c|}{ Hepatic encephalopathy } \\
\hline $\mathrm{No}^{*}$ & 1 & \\
\hline Yes & $5.22(1.77-15.40)$ & 0.003 \\
\hline \multicolumn{3}{|l|}{ Albumin } \\
\hline Per unit & $0.80(0.51-1.27)$ & 0.350 \\
\hline \multicolumn{3}{|l|}{ INR } \\
\hline Per unit & $2.75(1.08-7.04)$ & 0.034 \\
\hline \multicolumn{3}{|l|}{ Bilirubin } \\
\hline Per unit & $1.02(0.94-1.10)$ & 0.668 \\
\hline
\end{tabular}

MODEL 2

\begin{tabular}{lcc}
\hline Parameters & OR $(95 \% \mathrm{CI})$ & P-value \\
\hline Group & 1 & \\
No ascites* & $1.27(0.50-3.20)$ & 0.615 \\
Grade 1 ascites & $1.26(0.51-3.12)$ & 0.613 \\
Grade 2-3 ascites & 1 & \\
$\beta$-blockers & $1.94(1.01-3.74)$ & $\mathbf{0 . 0 4 8}$ \\
No & & \\
Yes & 1 & $\mathbf{0 . 0 3 0}$ \\
Diuretics & $3.48(1.13-10.75)$ & \\
No & & \\
Yes & 1 & $\mathbf{0 . 0 2 4}$ \\
CP stage & $2.98(1.15-7.68)$ & $<\mathbf{0 . 0 0 1}$ \\
A $^{*}$ & $6.79(2.31-19.90)$ & \\
B & & \\
C &
\end{tabular}

$($ Contd...) 
Table 3 (Continued)

\begin{tabular}{|c|c|c|}
\hline \multicolumn{3}{|c|}{ Hepatorenal syndrome development } \\
\hline \multicolumn{3}{|c|}{ MODEL 1} \\
\hline Parameters & OR (95\%CI) & P-value \\
\hline \multicolumn{3}{|l|}{ Group } \\
\hline No ascites ${ }^{\star}$ & 1 & \\
\hline Grade 1 ascites & $4.59(0.48-43.60)$ & 0.184 \\
\hline Grade 2-3 ascites & $3.68(0.39-35.07)$ & 0.257 \\
\hline \multicolumn{3}{|l|}{ Sex } \\
\hline Female $^{*}$ & 1 & \\
\hline Male & $6.19(0.79-48.20)$ & 0.082 \\
\hline \multicolumn{3}{|l|}{ Diuretics } \\
\hline $\mathrm{No}^{*}$ & 1 & \\
\hline Yes & $2.14(0.77-6.01)$ & 0.147 \\
\hline \multicolumn{3}{|l|}{ CP stage } \\
\hline$A^{*}$ & 1 & \\
\hline B & $2.21(0.44-11.10)$ & 0.335 \\
\hline $\mathrm{C}$ & $2.63(0.45-15.43)$ & 0.284 \\
\hline \multicolumn{3}{|l|}{$\beta$-blockers } \\
\hline $\mathrm{No}^{*}$ & 1 & \\
\hline Yes & $11.98(1.57-91.53)$ & 0.017 \\
\hline
\end{tabular}

MODEL 2

\begin{tabular}{lcc}
\hline Parameters & OR $(95 \% \mathrm{CI})$ & P-value \\
\hline Group & 1 & \\
No ascites & & \\
Grade 1 ascites & $6.74(0.4-61.43)$ & 0.091 \\
Grade 2-3 ascites & $4.80(0.52-44.37)$ & 0.167 \\
Diuretics & 1 & \\
No $^{*}$ & $2.06(0.73-5.77)$ & 0.171 \\
Yes & 1 & \\
$\beta$-blockers & $11.95(1.57-91.06)$ & $\mathbf{0 . 0 1 7}$ \\
No* & & \\
Yes & $1.07(0.82-1.40)$ & 0.630 \\
CP score & & \\
per unit &
\end{tabular}

Infection development

\begin{tabular}{lcc}
\hline Parameters & OR $(95 \% \mathrm{CI})$ & P-value \\
\hline Group & 1 & \\
No ascites & & \\
Grade 1 ascites & $1.58(0.83-3.04)$ & 0.166 \\
Grade 2-3 ascites & $2.22(1.22-4.06)$ & $\mathbf{0 . 0 0 9}$ \\
\hline & & $($ Contd...)
\end{tabular}

Table 3 (Continued)

\begin{tabular}{|c|c|c|}
\hline \multicolumn{3}{|c|}{ Infection development } \\
\hline \multicolumn{3}{|l|}{ Sex } \\
\hline Female $^{*}$ & 1 & \\
\hline Male & $1.81(0.96-3.41)$ & 0.069 \\
\hline \multicolumn{3}{|c|}{ Hepatic encephalopathy } \\
\hline $\mathrm{No}^{*}$ & 1 & \\
\hline Yes & $6.30(2.12-18.78)$ & 0.001 \\
\hline \multicolumn{3}{|l|}{ MELD } \\
\hline Per unit & $1.05(0.99-1.10)$ & 0.094 \\
\hline \multicolumn{3}{|c|}{ SBP Development } \\
\hline Parameters & OR $(95 \% \mathrm{CI})$ & $\mathrm{P}$-value \\
\hline \multicolumn{3}{|l|}{ Group } \\
\hline No ascites ${ }^{*}$ & 1 & \\
\hline Grade 1 ascites & $7.13(0.81-62.88)$ & 0.077 \\
\hline Grade $2-3$ ascites & $23.07(2.87-185.18)$ & 0.003 \\
\hline \multicolumn{3}{|l|}{ Sex } \\
\hline Female $^{*}$ & 1 & \\
\hline Male & $2.56(0.82-7.98)$ & 0.106 \\
\hline \multicolumn{3}{|l|}{$\beta$-blockers } \\
\hline $\mathrm{No}^{*}$ & 1 & \\
\hline Yes & $0.60(0.25-1.44)$ & 0.254 \\
\hline \multicolumn{3}{|l|}{ Diuretics } \\
\hline $\mathrm{No}^{*}$ & 1 & \\
\hline Yes & $0.96(0.44-2.09)$ & 0.918 \\
\hline \multicolumn{3}{|l|}{ Albumin } \\
\hline Per unit & $0.77(0.42-1.40)$ & 0.387 \\
\hline \multicolumn{3}{|l|}{ MELD } \\
\hline Per unit & $1.01(0.93-1.11)$ & 0.761 \\
\hline \multicolumn{3}{|l|}{ Sodium } \\
\hline Per unit & $0.96(0.87-1.05)$ & 0.371 \\
\hline
\end{tabular}

* Reference category

$O R$, odds ratio; INR, International normalized ratio; CI, confidence interval; CP, Child-Pugh; MELD, model for end-stage liver disease

related to HRS development are presented in Supplementary Table 1. Multivariate analysis for the total population (Table 3) determined that the use of $\beta$-blockers was the only independent prognostic factor for HRS development. The same analyses were performed in the group of patients with ascites grade 1 (Supplementary Table 2); in the multivariate analysis no variable was found to be associated with HRS development.

\section{Infection}

Thirty-two patients with ascites grade 1 (32\%), 51 patients with ascites grade $2 / 3(35.2 \%)$ and 26 patients 
with no ascites (14.9\%) developed infection during follow up $(\mathrm{P}<0.001)$. In the group of patients with ascites grade 1 , 7 patients (24.1\%) developed SBP. Patients who developed SBP were under treatment with diuretics. At the time of SBP infection, 6 of them had grade $2 / 3$ ascites and 1 patient had grade 1 ascites. At the last follow up, 6 SBP infected patients had grade $2 / 3$ ascites, 1 patient had no ascites and none of them had grade 1 ascites $(P=0.023)$. The factors associated with the development of infection are presented in Supplementary Table 1. In the multivariate analysis (Table 3 ), ascites grade $2 / 3$ and the presence of $\mathrm{HE}$ at baseline were independently correlated with infection development and ascites grade $2 / 3$ was the only predictor for SBP development (Table 3).

\section{Survival analysis}

\section{Total population}

During follow up, 166 of 420 patients died, with a cumulative mortality rate of $39.5 \%$. In the univariate analysis, the factors associated with patients' survival are presented in the Supplementary Table 3. In the multivariate analysis, age (hazard ratio [HR] 1.03, 95\%CI 1.02-1.05; $\mathrm{P}<0.001$ ), diabetes mellitus (DM) (HR 1.53, 95\%CI 1.03-2.28; $\mathrm{P}=0.036)$, and the CP stage C (HR 2.30, 95\%CI 1.37-3.85; $\mathrm{P}=0.002)$ were demonstrated as significant independent prognostic factors for patients' survival (Table 4).

\section{Ascites 1 group}

During follow up, 36 of 100 patients died, with a cumulative mortality rate of $36 \%$. In the multivariate analysis, 2 models were constructed (Table 4 ). The first model included creatinine, CP stage, HCC, and age. HCC (HR 4.84, 95\%CI 1.08-21.70; $\mathrm{P}=0.040)$, age (HR 1.04, 95\%CI 1.00-1.08; $\mathrm{P}=0.048)$, and creatinine (HR 1.39, 95\%CI 1.11-1.75; $\mathrm{P}=0.005)$ were found to be significantly related to patients' survival. The second model included MELD score, albumin, HCC, and age. Age (HR 1.05, 95\%CI 1.01-1.09; $\mathrm{P}=0.014$ ) and albumin (HR 0.46, 95\%CI 0.23-0.93; $\mathrm{P}=0.031$ ) were independently correlated with patients' survival.

\section{Ascites 2-3 group}

During follow up, 73 of 145 patients died of all causes, with a cumulative mortality rate of $50 \%$. For the multivariate analysis, 2 models, including DM, age and CP score and DM, age and MELD score, were constructed (Table 4). In the first model, only age (HR 1.04, 95\%CI 1.01-1.06; $\mathrm{P}=0.002$ ) was demonstrated as a predictor of mortality. In contrast, the second model, apart from age (HR 1.04, 95\%CI 1.02-1.06; $\mathrm{P}=0.001$ ), also demonstrated that MELD score (HR 1.09, 95\%CI 1.03-1.16; $\mathrm{P}=0.006$ ) was an independent predictor of survival.
Table 4 Multivariate cox regression analysis for patients' survival

\begin{tabular}{|c|c|c|}
\hline \multicolumn{3}{|c|}{ Total population } \\
\hline Parameters & HR $(95 \% \mathrm{CI})$ & P-value \\
\hline \multicolumn{3}{|c|}{ Intrinsic renal disease } \\
\hline $\mathrm{No}^{*}$ & 1 & \\
\hline Yes & $2.02(0.86-4.74)$ & 0.107 \\
\hline \multicolumn{3}{|l|}{ HCC } \\
\hline $\mathrm{No}^{*}$ & 1 & \\
\hline Yes & $1.16(0.51-2.63)$ & 0.729 \\
\hline \multicolumn{3}{|c|}{ Ischemic heart disease } \\
\hline $\mathrm{No}^{*}$ & 1 & \\
\hline Yes & $1.66(0.74-3.70)$ & 0.218 \\
\hline \multicolumn{3}{|c|}{ Diabetes mellitus } \\
\hline $\mathrm{No}^{*}$ & 1 & \\
\hline Yes & $1.53(1.03-2.28)$ & 0.036 \\
\hline \multicolumn{3}{|l|}{ Age } \\
\hline per unit & $1.03(1.02-1.05)$ & $<0.001$ \\
\hline \multicolumn{3}{|l|}{ CP stage } \\
\hline $\mathrm{A}^{*}$ & 1 & \\
\hline B & $1.15(0.78-1.69)$ & 0.491 \\
\hline $\mathrm{C}$ & $2.30(1.37-3.85)$ & 0.002 \\
\hline
\end{tabular}

ASCITES 1 GROUP

\begin{tabular}{lcc}
\hline \multicolumn{3}{c}{ MODEL 1} \\
\hline Parameters & HR $(95 \% \mathrm{CI})$ & P-value \\
\hline HCC & 1 & \\
No* & & \\
Yes & $4.84(1.08-21.70)$ & $\mathbf{0 . 0 4 0}$ \\
Age & & \\
per unit & $1.04(1.00-1.08)$ & $\mathbf{0 . 0 4 8}$ \\
Creatinine & & \\
per unit & $1.39(1.11-1.75)$ & $\mathbf{0 . 0 0 5}$ \\
CP stage & 1 & \\
A $^{*}$ & $1.97(0.62-6.33)$ & 0.253 \\
B & $2.66(0.66-10.70)$ & 0.168 \\
C & & \\
\hline
\end{tabular}

MODEL 2

\begin{tabular}{lcc}
\hline Parameters & HR $(95 \% \mathrm{CI})$ & P-value \\
\hline HCC & 1 & \\
No $^{*}$ & $3.78(0.96-14.89)$ & 0.057 \\
Yes & \\
\hline
\end{tabular}

(Contd...) 
Table 4 (Continued)

\begin{tabular}{lcc}
\hline \multicolumn{3}{c}{ MODEL 2 } \\
\hline Parameters & HR $(95 \% \mathrm{CI})$ & P-value \\
\hline $\begin{array}{l}\text { Age } \\
\text { per unit }\end{array}$ & $1.05(1.01-1.09)$ & $\mathbf{0 . 0 1 4}$ \\
$\begin{array}{l}\text { Albumin } \\
\text { per unit } \\
\text { MELD score } \\
\text { per unit }\end{array}$ & $0.46(0.23-0.93)$ & $\mathbf{0 . 0 3 1}$ \\
\hline
\end{tabular}

ASCITES 2/3 GROUP

MODEL 1

\begin{tabular}{lcc}
\hline Parameters & HR $(95 \% \mathrm{CI})$ & P-value \\
\hline Diabetes mellitus & 1 & \\
No $^{*}$ & $1.67(0.93-2.98)$ & 0.086 \\
Yes & $1.04(1.01-1.06)$ & $\mathbf{0 . 0 0 2}$ \\
Age & & \\
per unit & & \\
CP score & & \\
per unit & $1.13(0.95-1.34)$ & 0.162 \\
\hline
\end{tabular}

MODEL 2

\begin{tabular}{lcc}
\hline Parameters & HR $(95 \% \mathrm{CI})$ & P-value \\
\hline $\begin{array}{l}\text { Diabetes mellitus } \\
\mathrm{No}^{*}\end{array}$ & 1 & \\
Yes & $1.52(0.89-2.60)$ & 0.127 \\
Age & $1.04(1.02-1.06)$ & $\mathbf{0 . 0 0 1}$ \\
per unit & & \\
MELD score & & \\
per unit & $1.09(1.03-1.16)$ & $\mathbf{0 . 0 0 6}$ \\
\hline
\end{tabular}

NO ASCITES GROUP

\begin{tabular}{|c|c|c|}
\hline Parameters & HR (95\%CI) & P-value \\
\hline \multicolumn{3}{|c|}{ Ischemic heart disease } \\
\hline $\mathrm{No}^{*}$ & 1 & \\
\hline Yes & $1.97(0.46-8.74)$ & 0.370 \\
\hline \multicolumn{3}{|l|}{ Age } \\
\hline per unit & $1.04(1.01-1.06)$ & 0.008 \\
\hline \multicolumn{3}{|l|}{ Albumin } \\
\hline per unit & $0.74(0.53-1.06)$ & 0.100 \\
\hline
\end{tabular}

\section{No ascites group}

During follow up, 57 of 175 patients died of all causes, with a cumulative mortality rate of $32.8 \%$. In the multivariate analysis, only age (HR 1.04, 95\%CI 1.01-1.06; $\mathrm{P}=0.008$ ) was independently correlated with survival (Table 4 ). The probability of overall survival in patients with ascites grade 1 , ascites grade $2 / 3$ and no ascites is presented in Fig. 1 . There was no difference in overall survival among the 3 groups (log-rank $=1.408, \mathrm{P}=0.484)$.

\section{Discussion}

To our knowledge, this study constitutes the first report on the natural history and clinical course of cirrhotic patients with ascites grade 1 , compared to patients with ascites grade $2 / 3$ or no ascites, followed-up for a mean period of 18.93 months. EASL guidelines have reported that there is no evidence regarding the natural history of ascites grade 1 and its progression to grade $2 / 3$ in patients with liver cirrhosis $[6,9]$. The present study shows that at the last follow up, $62 \%$ of patients with grade 1 ascites had regression or stability of ascites, while $38 \%$ of patients had worsening ascites. Grade 1 ascites was not found to be an independent predictor of grade $2 / 3$ ascites. The initiation of diuretics was not correlated with regression of ascites at baseline or during follow up. The risk for SBP infection was low and occurred mainly in patients who developed worsening ascites. The mortality risk was similar to that of non-ascitic patients. These results indicate that the existence of grade 1 ascites in patients with liver cirrhosis does not represent a risk factor for the development of worsening ascites and suggest that there is no need for treatment with diuretics.

Development of ascites is the most common complication in patients who have liver cirrhosis, with approximately $60 \%$ of patients developing ascites within 10 years. Ascites' emergence and progression indicate a poor prognosis for patients, with a mortality of approximately $40 \%$ after 1 year [17-19]. Numerous reports have evaluated the natural history of liver disease of various etiologies [20-24]. Two studies have examined the natural history of patients hospitalized for the management of ascites in a cirrhotic population and have identified the prognostic factors associated with ascites progression $[8,25]$. Nevertheless, both studies included patients with clinically significant ascites (grade 2/3) $[8,25]$.

The current study evaluated the development of the main comorbid disorders closely associated with ascites progression. HRS developed in $10 \%$ of ascites grade 1 patients, in $7.6 \%$ of those with ascites grade $2 / 3$ and in $0.6 \%$ of patients with no ascites during follow up. Studies have shown variation among HRS rates in patients with ascites $(11.4 \%$ in 5 years [8] and $3 \%$ at 8.1 months [25]). These discrepancies could be explained by the variation in ascites severity and duration of follow up between these studies. Our study revealed that the use of $\beta$-blockers was the only independent predictive factor of 


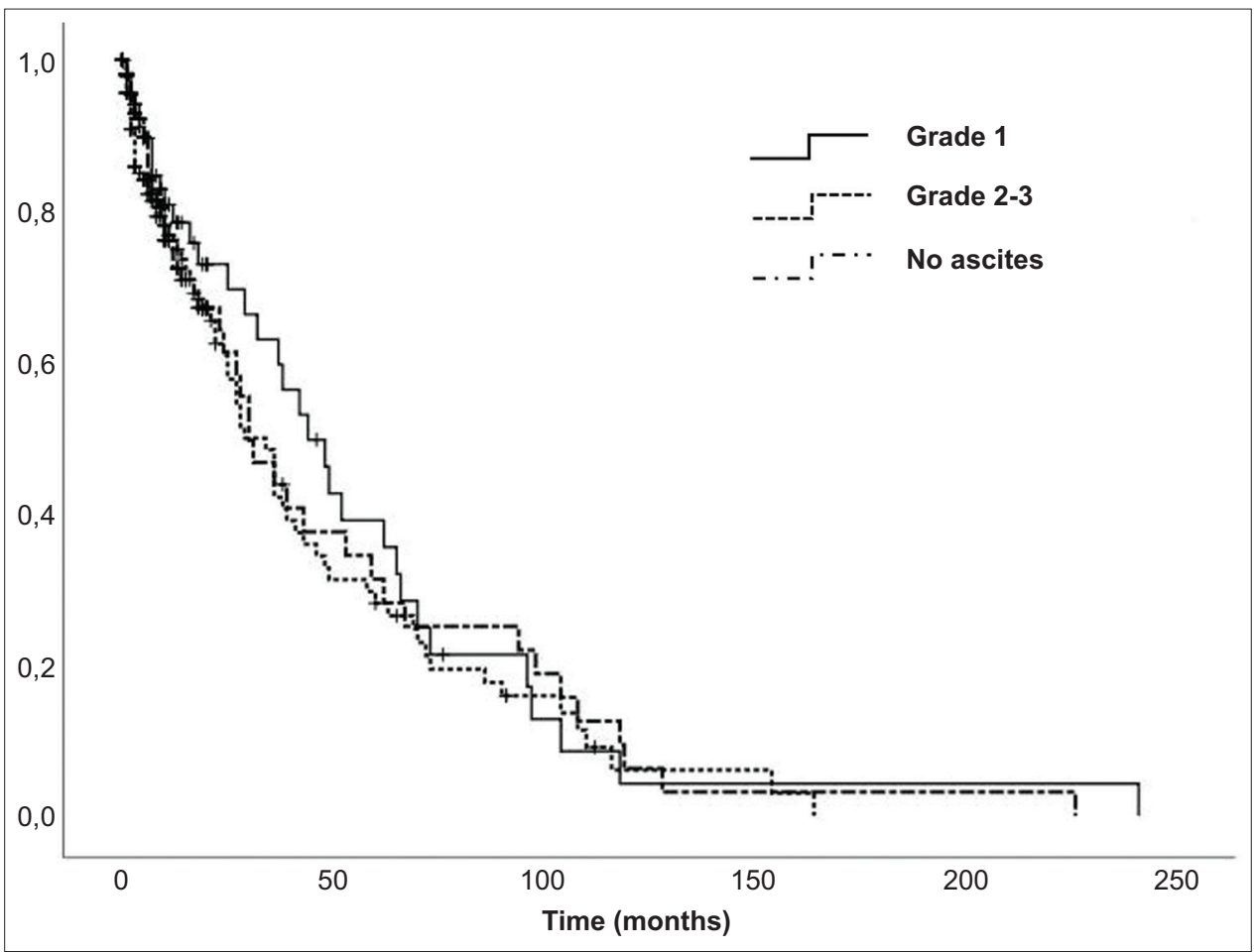

Figure 1 Kaplan-Meier curves for the cumulative probability of survival in patients with grade 1, 2/3 and no ascites

HRS development during follow up. A possible explanation of this finding could be the presence of concomitant SBP infection $(63.6 \%)$ in a high percentage of HRS patients in this cohort. The progression from cirrhosis with ascites to HRS development represents a pathophysiologic continuity driven by the existence of sinusoidal portal hypertension and systemic arterial vasodilation. Consequently, one explanation for the association between $\beta$-blocker intake and HRS development could be the severity of the underlying portal hypertension (grade of varices, etc.) as reflected by the clinical portal hypertension-related clinical events in Table 2.

The development of infection during follow up was also assessed in this cohort: $32 \%$ of patients with ascites grade 1 , $35.2 \%$ of patients with ascites grade $2 / 3$ and $14.9 \%$ of patients with no ascites were found to develop infection during the follow-up period. Patients with cirrhosis are at increased risk of developing bacterial infections [26,27]. In patients with liver cirrhosis and ascites, one of the most serious complications is the development of SBP, as it is associated with a high 1-year mortality rate $(30 \%$ to $90 \%)$ [28,29]. Several studies have examined the prevalence of SBP in patients with liver cirrhosis and ascites, which ranged between $10 \%$ and 30\% [30-31]. However, one study reported a significantly higher prevalence of SBP infection (67.7\%), in part explained by the small number and the advanced CP stage of the included patients [32]. In the present study, $7 \%$ of cirrhotic patients with ascites 1 developed SBP infection during follow up. However, at the time of infection only 1 patient had grade 1 ascites; the remaining 6 patients had grade $2 / 3$. Moreover, the multivariate analysis demonstrated that the development of SBP was independently associated with grade $2 / 3$ ascites, in contrast to grade 1 . These results strengthen the suggestion that there is no requirement for specific treatment in patients with ascites grade 1 .

The significance of $\mathrm{HE}$ as a prognostic marker in cirrhotic patients with ascites has been demonstrated, as it is associated with short survival in this population [33]. In this study, 23\% of patients with ascites grade $1,24.8 \%$ of those with ascites grade $2 / 3$ and $5.7 \%$ of patients with no ascites developed HE during follow up. A previous report revealed a greater degree of HE development, at a rate of $32.1 \%$, in cirrhotic patients [25]; however, that study concerned patients with moderate or severe ascites [25].

It is worth noting the high infection and HE rate of ascites grade 1 patients, which is comparable to ascites $2 / 3$ patients, but significantly higher than in patients without ascites; this is in contrast to the other complications investigated in this study. Although this finding did not reach statistical significance in the multivariate analysis, it may indicate that patients need particular attention in that direction and should be made a subject of investigation by future studies. Moreover, the similar risk of developing complications such as HE, HRS or infections between patients with grade 1 and grade $2 / 3$ ascites may indicate that the presence and not the grade of ascites could impact specific outcomes.

Ascites appearance indicates a poor prognosis, as the 5 -year survival decreases from about $80 \%$ in patients with compensated cirrhosis to about $30 \%$ in decompensated patients with ascites [2]. The overall survival rate in the total population of this study was $60.5 \%$. Previous studies reported lower survival rates (18.7-56.5\%) compared to the present 
results $[8,25,34]$. However, those studies included patients with clinically significant ascites [8,25,34]. Survival analysis in our patients demonstrated similar survival rates among all examined groups $(\mathrm{P}>0.05)$ : grade 1 patients $(64 \%)$ vs. grade $2 / 3$ patients (50\%) vs. non-ascites group (67.2\%).

Some limitations of the current study should be acknowledged. First, the fact that the cessation of alcohol intake was based on the patients' medical record; second, the retrospective nature of the study; and last, the omission of urine sodium measurement. The patients' compliance with the sodium restriction could have been monitored by measurement of urinary sodium excretion. However, considering the physician-imposed salt restriction, the patients' compliance was taken for granted.

In conclusion, these results suggest that the presence of grade 1 ascites does not constitute a precursor of grade $2 / 3$ ascites in patients with cirrhosis; therefore, patients with grade 1 ascites do not require specific treatment.

\section{Summary Box}

\section{What is already known:}

- Ascites is the most common major complication of cirrhosis and constitutes a critical landmark in the natural history of chronic liver disease

- Patients with ascites grade 1 do not require specific treatment, but should be followed up carefully and advised to reduce their sodium intake, since they usually progress to the development of grade 2 ascites, according to the International Club of Ascites

- There are no data on the evolution of grade 1 ascites, nor it is known whether its treatment modifies its natural history, according to the European Association for the Study of the Liver (EASL) guidelines

- No data exist on how frequently patients with grade 1 will develop grade 2 or 3 ascites, according to the EASL guidelines

\section{What the new findings are:}

- Grade 1 ascites does not constitute an independent predictor of grade 2 or 3 ascites in patients with liver cirrhosis

- There is no need for treatment with diuretics in cirrhotic patients with grade 1 ascites

\section{References}

1. Alessandria C, Ozdogan O, Guevara M, et al. MELD score and clinical type predict prognosis in hepatorenal syndrome: relevance to liver transplantation. Hepatology 2005;41:1282-1289.
2. D’Amico G, Garcia-Tsao G, Pagliaro L. Natural history and prognostic indicators of survival in cirrhosis: a systematic review of 118 studies. J Hepatol 2006;44:217-231.

3. Ginès A, Escorsell A, Ginès P, et al. Incidence, predictive factors, and prognosis of the hepatorenal syndrome in cirrhosis with ascites. Gastroenterology 1993;105:229-236.

4. Glück Z, Nolph KD. Ascites associated with end-stage renal disease. Am J Kidney Dis 1987;10:9-18.

5. Moore KP, Wong F, Gines P, et al. The management of ascites in cirrhosis: report on the consensus conference of the International Ascites Club. Hepatology 2003;38:258-266.

6. Angeli P, Bernardi M, Villanueva C, et al; European Association for the Study of the Liver. Corrigendum to "EASL Clinical Practice Guidelines for the management of patients with decompensated cirrhosis". J Hepatol 2018;69:1207.

7. Lee JM, Han KH, Ahn SH. Ascites and spontaneous bacterial peritonitis: an Asian perspective. $J$ Gastroenterol Hepatol 2009;24:1494-1503.

8. Planas R, Montoliu S, Ballesté B, et al. Natural history of patients hospitalized for management of cirrhotic ascites. Clin Gastroenterol Hepatol 2006;4:1385-1394.

9. European Association for the Study of the Liver. EASL clinical practice guidelines on the management of ascites, spontaneous bacterial peritonitis, and hepatorenal syndrome in cirrhosis. $J$ Hepatol 2010;53:397-417.

10. Garcia-Tsao G, Lim JK, Lim J; Members of Veterans Affairs Hepatitis C Resource Center Program. Management and treatment of patients with cirrhosis and portal hypertension: recommendations from the Department of Veterans Affairs Hepatitis C Resource Center Program and the National Hepatitis C Program. Am J Gastroenterol 2009;104:1802-1829.

11. Wiegand J, Berg T. The etiology, diagnosis and prevention of liver cirrhosis: part 1 of a series on liver cirrhosis. Dtsch Arztebl Int 2013;110:85-91.

12. Chen K, Cao X, Zheng Y, Xu M, Peng J. Comparative study of the MELD-Na and Child-Turcotte-Pugh scores as short-term prognostic indicators of acute-on-chronic hepatitis B liver failure. Zhonghua Gan Zang Bing Za Zhi 2014;22:801-805.

13. Rimola A, García-Tsao G, Navasa M, et al. Diagnosis, treatment and prophylaxis of spontaneous bacterial peritonitis: a consensus document. International Ascites Club. J Hepatol 2000;32:142-153.

14. Vilstrup H, Amodio P, Bajaj J, et al. Hepatic encephalopathy in chronic liver disease: 2014 Practice Guideline by the American Association for the Study of Liver Diseases and the European Association for the Study of the Liver. Hepatology 2014;60:715-735.

15. Angeli $P$, Ginès $P$, Wong $F$, et al. Diagnosis and management of acute kidney injury in patients with cirrhosis: revised consensus recommendations of the International Club of Ascites. $J$ Hepatol 2015;62:968-974.

16. European Association for the Study of the Liver. EASL Clinical Practice Guidelines: Management of alcohol-related liver disease. J Hepatol 2018;69:154-181.

17. Ginés P, Quintero E, Arroyo V, et al. Compensated cirrhosis: natural history and prognostic factors. Hepatology 1987;7:122-128.

18. Marchesini G, Bianchi G, Amodio P, et al; Italian Study Group for quality of life in cirrhosis. Factors associated with poor healthrelated quality of life of patients with cirrhosis. Gastroenterology 2001;120:170-178.

19. Vicco MH, Rodeles L, Ferini F, Long AK, Musacchio HM. Inhospital mortality risk factors in patients with ascites due to cirrhosis. Rev Assoc Med Bras (1992) 2015;61:35-39.

20. Busch K, Thimme R. Natural history of chronic hepatitis B virus infection. Med Microbiol Immunol 2015;204:5-10.

21. Calzadilla BL, Adams LA. The natural course of non-alcoholic fatty 
liver disease. Int J Mol Sci 2016;17:774.

22. Imam MH, Lindor KD. The natural history of primary biliary cirrhosis. Semin Liver Dis 2014;34:329-333.

23. Schwartz JM, Reinus JF. Prevalence and natural history of alcoholic liver disease. Clin Liver Dis 2012;16:659-666.

24. Westbrook RH, Dusheiko G. Natural history of hepatitis C. J Hepatol 2014;61:S58-S68.

25. Kim SU, Han KH, Nam CM, et al. Natural history of hepatitis B virus-related cirrhotic patients hospitalized to control ascites. $J$ Gastroenterol Hepatol 2008;23:1722-1727.

26. Fernández J, Gustot T. Management of bacterial infections in cirrhosis. J Hepatol 2012;56(Suppl 1):S1-S12.

27. Jalan R, Fernandez J, Wiest R, et al. Bacterial infections in cirrhosis: a position statement based on the EASL Special Conference 2013. J Hepatol 2014;60:1310-1324.

28. Fernández J, Navasa M, Gómez J, et al. Bacterial infections in cirrhosis: epidemiological changes with invasive procedures and norfloxacin prophylaxis. Hepatology 2002;35:140-148.
29. Sundaram V, Manne V, Al-Osaimi AM. Ascites and spontaneous bacterial peritonitis: recommendations from two United States centers. Saudi J Gastroenterol 2014;20:279-287.

30. Evans LT, Kim WR, Poterucha JJ, Kamath PS. Spontaneous bacterial peritonitis in asymptomatic outpatients with cirrhotic ascites. Hepatology 2003;37:897-901.

31. Schwabl P, Bucsics T, Soucek K, et al. Risk factors for development of spontaneous bacterial peritonitis and subsequent mortality in cirrhotic patients with ascites. Liver Int 2015;35:2121-2128.

32. Oladimeji AA, Temi AP, Adekunle AE, Taiwo RH, Ayokunle DS. Prevalence of spontaneous bacterial peritonitis in liver cirrhosis with ascites. Pan Afr Med J 2013;15:128.

33. Dhiman RK, Kurmi R, Thumburu KK, et al. Diagnosis and prognostic significance of minimal hepatic encephalopathy in patients with cirrhosis of liver. Dig Dis Sci 2010;55:2381-2390.

34. Fernández-Esparrach G, Sánchez-Fueyo A, Ginès $P$, et al. A prognostic model for predicting survival in cirrhosis with ascites. $J$ Hepatol 2001;34:46-52. 


\section{Supplementary material}

Supplementary Table 1 Univariate analyses of factors correlating with the main comorbid disorders that accompany ascites progression in the total population

\begin{tabular}{|c|c|c|c|c|c|c|c|c|}
\hline \multirow[t]{2}{*}{ Characteristics } & \multicolumn{2}{|l|}{$\mathrm{HE}$} & \multicolumn{2}{|l|}{ HRS } & \multicolumn{2}{|l|}{ Infection } & \multicolumn{2}{|l|}{ SBP } \\
\hline & OR $(95 \% \mathrm{CI})$ & $\mathrm{P}$-value & OR $(95 \% \mathrm{CI})$ & P-value & OR $(95 \% \mathrm{CI})$ & P-value & OR $(95 \% \mathrm{CI})$ & P-value \\
\hline \multicolumn{9}{|l|}{ Group } \\
\hline No ascites* & 1 & & 1 & & 1 & & 1 & \\
\hline Grade 1 ascites & $4.87(2.21-10.73)$ & $<0.001$ & $19.32(2.43-153.39)$ & 0.005 & $2.53(1.40-4.59)$ & 0.002 & $4.29(1.08-16.98)$ & 0.038 \\
\hline Grade $2 / 3$ ascites & $5.38(2.57-11.30$ & $<0.001$ & $14.02(1.79-109.90)$ & 0.012 & $2.89(1.69-4.96)$ & $<0.001$ & $14.13(4.21-47.46)$ & $<0.001$ \\
\hline \multicolumn{9}{|l|}{ Sex } \\
\hline Female $^{*}$ & 1 & & 1 & & 1 & & 1 & \\
\hline Male & $0.63(0.33-1.24)$ & 0.181 & $7.00(0.93-52.71)$ & 0.059 & $1.94(1.09-3.46)$ & 0.024 & $2.95(1.02-8.51)$ & 0.046 \\
\hline \multicolumn{9}{|c|}{ Intrinsic renal disease } \\
\hline $\mathrm{No}^{*}$ & 1 & & 1 & & 1 & & 1 & \\
\hline Yes & $0.52(0.16-1.70)$ & 0.281 & $0.78(0.10-6.18)$ & 0.810 & $1.28(0.43-3.77)$ & 0.655 & $0.66(0.08-5.11)$ & 0.687 \\
\hline \multicolumn{9}{|l|}{ Diabetes mellitus } \\
\hline $\mathrm{No}^{*}$ & 1 & & 1 & & 1 & & 1 & \\
\hline Yes & $0.67(0.37-1.22)$ & 0.187 & $1.17(0.39-3.55)$ & 0.784 & $1.13(0.66-1.92)$ & 0.656 & $0.86(0.36-2.01)$ & 0.719 \\
\hline \multicolumn{9}{|c|}{ Non-HCC malignancy } \\
\hline $\mathrm{No}^{*}$ & & & 1 & & 1 & & 1 & \\
\hline Yes & NA & & $1.50(0.19-11.56)$ & 0.700 & $0.47(0.16-1.38)$ & 0.169 & $0.37(0.05-2.77)$ & 0.329 \\
\hline \multicolumn{9}{|l|}{ Lung disease } \\
\hline $\mathrm{No}^{*}$ & 1 & & 1 & & 1 & & 1 & \\
\hline Yes & $0.59(0.24-1.44)$ & 0.247 & $0.45(0.13-1.62)$ & 0.222 & $1.51(0.68-3.37)$ & 0.309 & $0.72(0.17-3.16)$ & 0.666 \\
\hline \multicolumn{9}{|l|}{ Smoking } \\
\hline $\mathrm{No}^{*}$ & 1 & & 1 & & 1 & & 1 & \\
\hline Yes & $0.98(0.58-1.68)$ & 0.948 & $0.91(0.38-2.19)$ & 0.836 & $1.30(0.83-2.06)$ & 0.254 & $1.32(0.66-2.63)$ & 0.435 \\
\hline \multicolumn{9}{|l|}{ Hypertension } \\
\hline $\mathrm{No}^{*}$ & 1 & & 1 & & 1 & & 1 & \\
\hline Yes & $2.04(0.93-4.45)$ & 0.074 & $2.48(0.57-10.82)$ & 0.228 & $0.64(0.35-1.17)$ & 0.146 & $0.45(0.15-1.29)$ & 0.497 \\
\hline \multicolumn{9}{|c|}{ Hepatic encephalopathy } \\
\hline $\mathrm{No}^{*}$ & 1 & & 1 & & 1 & & 1 & \\
\hline Yes & $8.97(3.51-22.92)$ & $<0.001$ & $0.48(0.10-2.20)$ & 0.341 & $6.70(2.48-18.12)$ & $<0.001$ & $3.59(1.23-10.48)$ & 0.019 \\
\hline \multicolumn{9}{|l|}{ Diuretics } \\
\hline $\mathrm{No}^{*}$ & 1 & & 1 & & 1 & & 1 & \\
\hline Yes & $8.27(2.94-23.25)$ & $<0.001$ & $4.97(1.90-12.98)$ & 0.001 & $2.09(1.34-3.26)$ & 0.001 & $2.43(1.25-4.74)$ & 0.009 \\
\hline \multicolumn{9}{|l|}{$\mathrm{CP}$ stage } \\
\hline $\mathrm{A}^{*}$ & 1 & & 1 & & 1 & & 1 & \\
\hline B & $5.63(2.44-13.01)$ & $<0.001$ & $9.13(1.78-46.77)$ & 0.008 & $2.66(1.52-4.67)$ & 0.001 & $2.45(0.94-6.34)$ & 0.067 \\
\hline $\mathrm{C}$ & $12.84(5.03-32.81)$ & $<0.001$ & $1.50(0.55-4.11)$ & 0.435 & $6.03(2.97-12.27)$ & $<0.001$ & $6.83(2.41-19.32)$ & $<0.001$ \\
\hline \multicolumn{9}{|l|}{$\beta$-blockers } \\
\hline $\mathrm{No}^{*}$ & 1 & & 1 & & 1 & & 1 & \\
\hline Yes & $3.35(1.84-6.09)$ & $<0.001$ & $19.46(2.59-146.05)$ & 0.004 & $2.89(1.79-4.66)$ & $<0.001$ & $0.38(0.18-0.79)$ & 0.010 \\
\hline
\end{tabular}


Supplementary Table 1 (Continued)

\begin{tabular}{|c|c|c|c|c|c|c|c|c|}
\hline \multirow[t]{2}{*}{ Characteristics } & \multicolumn{2}{|l|}{$\mathrm{HE}$} & \multicolumn{2}{|l|}{ HRS } & \multicolumn{2}{|l|}{ Infection } & \multicolumn{2}{|l|}{ SBP } \\
\hline & OR $(95 \% \mathrm{CI})$ & P-value & OR $(95 \% \mathrm{CI})$ & P-value & OR (95\% CI) & $\mathrm{P}$-value & OR $(95 \% \mathrm{CI})$ & P-value \\
\hline \multicolumn{9}{|l|}{ PVT } \\
\hline $\mathrm{No}^{*}$ & & & 1 & & 1 & & 1 & \\
\hline Yes & NA & & $5.82(1.94-17.46)$ & 0.002 & $0.39(0.05-3.22)$ & 0.383 & $1.41(0.17-11.73)$ & 0.753 \\
\hline \multicolumn{9}{|l|}{ HCC } \\
\hline $\mathrm{No}^{*}$ & & & 1 & & 1 & & 1 & \\
\hline Yes & NA & & $0.88(0.11-6.99)$ & 0.907 & $0.36(0.08-1.60)$ & 0.178 & $0.60(0.08-4.65)$ & 0.625 \\
\hline \multicolumn{9}{|l|}{ Age (years) } \\
\hline per unit & $1.00(0.98-1.02)$ & 0.979 & $0.98(0.95-1.01)$ & 0.193 & $0.99(0.97-1.01)$ & 0.207 & $1.00(0.97-1.02)$ & 0.890 \\
\hline \multicolumn{9}{|l|}{ Plt } \\
\hline per unit & $1.00(0.99-1.00)$ & 0.106 & $1.00(1.00-1.01)$ & 0.334 & $1.00(1.00-1.00)$ & 0.439 & $1.00(0.99-1.00)$ & 0.231 \\
\hline \multicolumn{9}{|l|}{ PT } \\
\hline per unit & $1.10(1.03-1.16)$ & 0.003 & $0.98(0.91-1.05)$ & 0.532 & $1.03(0.99-1.08)$ & 0.144 & $1.02(0.97-1.08)$ & 0.406 \\
\hline \multicolumn{9}{|l|}{ INR } \\
\hline per unit & $5.61(2.45-12.83)$ & $<0.001$ & $1.00(0.48-2.08)$ & 0.998 & $1.43(0.89-2.30)$ & 0.145 & $1.22(0.83-1.81)$ & 0.318 \\
\hline \multicolumn{9}{|l|}{ Sodium } \\
\hline per unit & $5.61(2.45-12.83)$ & $<0.001$ & $1.04(0.94-1.15)$ & 0.482 & $0.97(0.92-1.03)$ & 0.336 & $0.91(0.84-0.99)$ & 0.023 \\
\hline \multicolumn{9}{|l|}{ Bilirubin } \\
\hline per unit & $1.10(1.03-1.19)$ & 0.008 & $1.00(0.87-1.14)$ & 0.943 & $1.11(1.03-1.19)$ & 0.007 & $1.07(0.99-1.16)$ & 0.090 \\
\hline \multicolumn{9}{|l|}{ Albumin } \\
\hline per unit & $0.57(0.40-0.80)$ & 0.001 & $0.60(0.36-1.01)$ & 0.053 & $0.61(0.45-0.83)$ & 0.001 & $0.57(0.37-0.088)$ & 0.010 \\
\hline \multicolumn{9}{|l|}{ Creatinine } \\
\hline per unit & $1,02(0.73-1.42)$ & 0.899 & $0.84(0.58-1.22)$ & 0.360 & $0.86(0.57-1.29)$ & 0.465 & $1.00(0.64-1.57)$ & 0.994 \\
\hline \multicolumn{9}{|l|}{ CP score } \\
\hline per unit & $1.56(1.35-1.81)$ & $<0.001$ & $1.34(1.08-1.66)$ & 0.008 & $1.40(1.24-1.59)$ & $<0.001$ & $1.49(1.24-1.78)$ & $<0.001$ \\
\hline \multicolumn{9}{|l|}{ MELD score } \\
\hline per unit & $1.18(1.11-1.25)$ & $<0.001$ & $0.94(0.87-1.02)$ & 0.114 & $1.08(1.03-1.14)$ & 0.001 & $1.08(1.01-1.15)$ & 0.026 \\
\hline
\end{tabular}

\footnotetext{
${ }^{*}$ Reference category
}

The indication NA concerns associations in which no patient or small sample size met the examined criteria and thus the association between these variables could not be evaluated by means of regression

HE, hepatic encephalopathy; HRS, hepatorenal syndrome; SBP, spontaneous bacterial peritonitis; OR, odds ratio; CI, confidence interval; HCC, hepatocellular carcinoma; NA, not applicable; CP, Child-Pugh; PVT, portal vein thrombosis; Plt, platelets; PT, prothrombin time; INR, international normalized ratio; MELD, model for end-stage liver disease

Supplementary Table 2 Univariate analyses of factors correlating with the main comorbid disorders that accompany ascites progression in the group of patients with ascites grade 1

\begin{tabular}{|c|c|c|c|c|}
\hline \multirow[t]{2}{*}{ Characteristics } & \multicolumn{2}{|c|}{$\mathrm{HE}$} & \multicolumn{2}{|c|}{ HRS } \\
\hline & OR $(95 \% \mathrm{CI})$ & P-value & OR $(95 \% \mathrm{CI})$ & P-value \\
\hline \multicolumn{5}{|l|}{ Sex } \\
\hline Female $^{*}$ & & & 1 & \\
\hline Male & & & $1.27(0.15-11.01)$ & 0.829 \\
\hline \multicolumn{5}{|c|}{ Intrinsic renal disease } \\
\hline $\mathrm{No}^{*}$ & & & 1 & \\
\hline Yes & & & $4.78(0.39-58.02)$ & 0.220 \\
\hline
\end{tabular}




\begin{tabular}{|c|c|c|c|c|}
\hline \multirow[t]{2}{*}{ Characteristics } & \multicolumn{2}{|c|}{$\mathrm{HE}$} & \multicolumn{2}{|c|}{ HRS } \\
\hline & OR $(95 \% \mathrm{CI})$ & $\mathrm{P}$-value & OR $(95 \% \mathrm{CI})$ & $\mathrm{P}$-value \\
\hline \multicolumn{5}{|c|}{ Diabetes mellitus } \\
\hline $\mathrm{No}^{*}$ & 1 & & 1 & \\
\hline Yes & $1.00(0.29-3.42)$ & $>0.99$ & $2.27(0.52-9.83)$ & 0.275 \\
\hline \multicolumn{5}{|c|}{ Non-HCC malignancy } \\
\hline $\mathrm{No}^{*}$ & & & 1 & \\
\hline Yes & & & $4.67(0.38-56.68)$ & 0.227 \\
\hline \multicolumn{5}{|l|}{ Lung disease } \\
\hline $\mathrm{No}^{*}$ & 1 & & 1 & \\
\hline Yes & $0.60(0.12-2.94)$ & 0.528 & $1.75(0.33-9.33)$ & 0.512 \\
\hline \multicolumn{5}{|l|}{ Smoking } \\
\hline $\mathrm{No}^{*}$ & 1 & & 1 & \\
\hline Yes & $1.10(0.42-2.89)$ & 0.846 & $0.74(0.20-2.73)$ & 0.645 \\
\hline \multicolumn{5}{|l|}{ Hypertension } \\
\hline $\mathrm{No}^{*}$ & 1 & & 1 & \\
\hline Yes & $0.87(0.26-2.94)$ & 0.823 & $1.06(0.21-5.44)$ & 0.945 \\
\hline \multicolumn{5}{|c|}{ Hepatic encephalopathy } \\
\hline $\mathrm{No}^{*}$ & 1 & & 1 & \\
\hline Yes & $2.55(0.30-21.54)$ & 0.390 & $1.13(0.13-10.05)$ & 0.916 \\
\hline \multicolumn{5}{|l|}{ Diuretics } \\
\hline $\mathrm{No}^{*}$ & 1 & & 1 & \\
\hline Yes & $2.98(0.63-13.97)$ & 0.167 & $3.04(0.61-15.15)$ & 0.175 \\
\hline \multicolumn{5}{|l|}{$\mathrm{CP}$ stage } \\
\hline $\mathrm{A}^{*}$ & 1 & & 1 & \\
\hline B & $0.27(0.05-1.50)$ & 0.134 & $0.59(0.05-7.07)$ & 0.676 \\
\hline $\mathrm{C}$ & $0.65(0.22-1.92)$ & 0.437 & $1.35(0.26-7.04)$ & 0.725 \\
\hline \multicolumn{5}{|l|}{$\beta$-blockers } \\
\hline $\mathrm{No}^{*}$ & 1 & & & \\
\hline Yes & $3.17(0.98-10.23)$ & 0.054 & & \\
\hline \multicolumn{5}{|l|}{ PVT } \\
\hline \multicolumn{5}{|l|}{$\mathrm{No}^{*}$} \\
\hline Yes & \multicolumn{2}{|c|}{ NA } & \multicolumn{2}{|c|}{ NA } \\
\hline \multicolumn{5}{|l|}{ HCC } \\
\hline \multicolumn{5}{|l|}{$\mathrm{No}^{*}$} \\
\hline Yes & \multicolumn{2}{|c|}{ NA } & \multicolumn{2}{|c|}{ NA } \\
\hline \multicolumn{5}{|l|}{ Age (years) } \\
\hline per unit & $0.97(0.93-1.00)$ & 0.079 & $1.00(0.95-1.05)$ & 0.985 \\
\hline \multicolumn{5}{|l|}{ Plt } \\
\hline per unit & $0.99(0.99-1.00)$ & 0.183 & $1.00(0.99-1.01)$ & 0.880 \\
\hline \multicolumn{5}{|l|}{ PT } \\
\hline per unit & $1.21(1.03-1.43)$ & 0.019 & $0.97(0.72-1.31)$ & 0.842 \\
\hline
\end{tabular}




\begin{tabular}{|c|c|c|c|c|}
\hline \multirow[t]{2}{*}{ Characteristics } & \multicolumn{2}{|c|}{$\mathrm{HE}$} & \multicolumn{2}{|c|}{ HRS } \\
\hline & OR $(95 \% \mathrm{CI})$ & P-value & OR $(95 \% \mathrm{CI})$ & P-value \\
\hline \multicolumn{5}{|l|}{ INR } \\
\hline per unit & $2.96(0.66-13.33)$ & 0.156 & $0.28(0.02-4.30)$ & 0.360 \\
\hline \multicolumn{5}{|l|}{ Sodium } \\
\hline per unit & $0.98(0.86-1.12)$ & 0.814 & $1.00(0.83-1.20)$ & 0.995 \\
\hline \multicolumn{5}{|l|}{ Bilirubin } \\
\hline per unit & $1.11(0.99-1.25)$ & 0.064 & $0.95(0.76-1.18)$ & 0.617 \\
\hline \multicolumn{5}{|l|}{ Albumin } \\
\hline per unit & $0.74(0.33-1.64)$ & 0.454 & $0.55(0.17-1.79)$ & 0.32 \\
\hline \multicolumn{5}{|l|}{ Creatinine } \\
\hline per unit & $0.78(0.27-2.31)$ & 0.659 & $1.11(0.70-1.76)$ & 0.670 \\
\hline \multicolumn{5}{|l|}{ CP score } \\
\hline per unit & $1.31(0.99-1.73)$ & 0.053 & $1.04(0.71-1.52)$ & 0.859 \\
\hline \multicolumn{5}{|l|}{ MELD score } \\
\hline per unit & $1.11(1.00-1.23)$ & 0.043 & $0.98(0.85-1.14)$ & 0.796 \\
\hline
\end{tabular}

The indication NA concerns associations in which no patient or small sample size met the examined criteria and thus the association between these variables could not be evaluated by means of regression

HE, hepatic encephalopathy; HRS, hepatorenal syndrome; OR, odds ratio; CI, confidence interval; HCC, hepatocellular carcinoma; CP, Child-Pugh; PVT, portal vein thrombosis; Plt, platelets; $P$ T, prothrombin time; INR, international normalized ratio; MELD, model for end-stage liver disease

Supplementary Table 3 Univariate Cox regression analysis for patients' survival

\begin{tabular}{|c|c|c|c|c|c|c|c|c|}
\hline \multirow[t]{2}{*}{ Characteristics } & \multicolumn{2}{|c|}{ Total population } & \multicolumn{2}{|c|}{ Ascites 1 group } & \multicolumn{2}{|c|}{ Ascites $2 / 3$ group } & \multicolumn{2}{|c|}{ No ascites group } \\
\hline & HR $(95 \% \mathrm{CI})$ & P-value & HR $(95 \% \mathrm{CI})$ & P-value & HR $(95 \% \mathrm{CI})$ & P-value & HR $(95 \% \mathrm{CI})$ & P-value \\
\hline \multicolumn{9}{|l|}{ Group } \\
\hline per unit & $1.09(0.86-1.28)$ & 0.639 & NA & & NA & & NA & \\
\hline \multicolumn{9}{|l|}{ Sex } \\
\hline per unit & $0.96(0.63-1.46)$ & 0.849 & $1.43(0.33-6.19)$ & 0.633 & $1.26(0.63-2.54)$ & 0.512 & $0.75(0.41-1.38)$ & 0.355 \\
\hline \multicolumn{9}{|c|}{ Intrinsic renal disease } \\
\hline per unit & $2.25(1.04-4.84)$ & 0.039 & $25.96(4.26-158.08)$ & $<0.001$ & $1.84(0.65-5.16)$ & 0.248 & $0.96(0.13-7.03)$ & 0.968 \\
\hline \multicolumn{9}{|c|}{ Diabetes mellitus } \\
\hline per unit & $1.63(1.15-2.32)$ & 0.006 & $1.57(0.64-3.86)$ & 0.325 & $1.68(1.02-2.78)$ & 0.043 & $1.48(0.81-2.72)$ & 0.201 \\
\hline \multicolumn{9}{|c|}{ Ischemic heart disease } \\
\hline per unit & $2.61(1.26-5.41)$ & 0.010 & $3.76(0.47-30.00)$ & 0.211 & $1.99(0.71-5.61)$ & 0.192 & $3.77(1.13-12.62)$ & 0.031 \\
\hline \multicolumn{9}{|c|}{ Non-HCC malignancy } \\
\hline per unit & $1.18(0.58-2.41)$ & 0.653 & NA & & $3.16(0.72,13.80)$ & 0.126 & $1.02(0.43,2.39)$ & 0.970 \\
\hline \multicolumn{9}{|l|}{ Lung disease } \\
\hline per unit & $1.60(0.88-2.89)$ & 0.121 & $1.31(0.49-3.45)$ & 0.589 & $1.56(0.48-5.02)$ & 0.457 & $2.13(0.76-5.99)$ & 0.150 \\
\hline \multicolumn{9}{|l|}{ Smoking } \\
\hline per unit & $0.79(0.58-1.09)$ & 0.152 & $0.50(0.24-1.02)$ & 0.057 & $1.13(0.68-1.89)$ & 0.640 & $0.63(0.36-1.09)$ & 0.095 \\
\hline \multicolumn{9}{|l|}{ Hypertension } \\
\hline per unit & $1.24(0.86-1.78)$ & 0.247 & $1.33(0.66-2.66)$ & 0.427 & $1.08(0.57-2.07)$ & 0.811 & $1.28(0.72-2.30)$ & 0.400 \\
\hline
\end{tabular}


Supplementary Table 3 (Continued)

\begin{tabular}{|c|c|c|c|c|c|c|c|c|}
\hline \multirow[t]{2}{*}{ Characteristics } & \multicolumn{2}{|c|}{ Total population } & \multicolumn{2}{|c|}{ Ascites 1 group } & \multicolumn{2}{|c|}{ Ascites $2 / 3$ group } & \multicolumn{2}{|c|}{ No ascites group } \\
\hline & HR $(95 \% \mathrm{CI})$ & P-value & HR $(95 \% \mathrm{CI})$ & P-value & HR (95\%CI) & P-value & HR $(95 \% \mathrm{CI})$ & $\mathrm{P}$-value \\
\hline \multicolumn{9}{|c|}{ Hepatic encephalopathy } \\
\hline per unit & $0.65(0.35-1.21)$ & 0.174 & $0.73(0.29-1.83)$ & 0.504 & $0.32(0.10-1.05)$ & 0.061 & $0.48(0.12-2.01)$ & 0.317 \\
\hline \multicolumn{9}{|l|}{ Diuretics } \\
\hline per unit & $1.06(0.74-1.51)$ & 0.769 & $2.40(0.95-6.06)$ & 0.065 & $1.04(0.30-3.70)$ & 0.946 & $0.95(0.56-1.62)$ & 0.854 \\
\hline \multicolumn{9}{|l|}{ CP stage } \\
\hline per unit & $1.34(1.03-1.74)$ & 0.030 & $1.54(0.85-2.79)$ & 0.150 & $1.31(0.77-2.22)$ & 0.326 & $1.27(0.63-2.55)$ & 0.506 \\
\hline \multicolumn{9}{|l|}{ Varices } \\
\hline per unit & $1.19(0.82-1.74)$ & 0.359 & $1.68(0.62-4.53)$ & 0.304 & $1.06(0.52-2.14)$ & 0.877 & $1.33(0.75-2.37)$ & 0.328 \\
\hline \multicolumn{9}{|l|}{ PVT } \\
\hline per unit & $0.12(0.03-0.44)$ & 0.001 & $0.12(0.03-0.44)$ & 0.001 & NA & & NA & \\
\hline \multicolumn{9}{|l|}{$\mathrm{HCC}$} \\
\hline per unit & $4.45(1.21-16.37)$ & 0.025 & $4.45(1.21-16.37)$ & 0.025 & NA & & NA & \\
\hline \multicolumn{9}{|l|}{$\beta$-blockers } \\
\hline per unit & $1.33(0.97-1.82)$ & 0.074 & $2.20(0.96-5.04)$ & 0.063 & NA & & NA & \\
\hline \multicolumn{9}{|l|}{ Age (years) } \\
\hline per unit & $1.04(1.02-1.05)$ & $<0.001$ & $1.05(1.02-1.09)$ & 0.005 & $1.03(1.01-1.05)$ & 0.003 & $1.04(1.02-1.07)$ & 0.001 \\
\hline \multicolumn{9}{|l|}{ Plt } \\
\hline per unit & $1.00(1.00-1.00)$ & 0.591 & $1.00(0.99-1.00)$ & 0.829 & $1.00(1.00-1.01)$ & 0.246 & $1.00(1.00-1.00)$ & 0.802 \\
\hline \multicolumn{9}{|l|}{ PT } \\
\hline per unit & $1.03(0.99-1.06)$ & 0.127 & $1.07(0.95-1.20)$ & 0.255 & $1.02(0.95-1.11)$ & 0.563 & $0.99(0.90-1.09)$ & 0.857 \\
\hline \multicolumn{9}{|l|}{ INR } \\
\hline per unit & $1.21(0.89-1.65)$ & 0.231 & $3.23(0.93-11.22)$ & 0.065 & $1.24(0.52-2.93)$ & 0.631 & $1.07(0.55-2.06)$ & 0.851 \\
\hline \multicolumn{9}{|l|}{ Sodium } \\
\hline per unit & $0.98(0.94-1.02)$ & 0.263 & $0.97(0.88-1.07)$ & 0.523 & $0.95(0.89-1.02)$ & 0.146 & $1.01(0.95-1.08)$ & 0.716 \\
\hline \multicolumn{9}{|l|}{ Bilirubin } \\
\hline per unit & $1.03(0.98-1.09)$ & 0.273 & $0.99(0.89-1.10)$ & 0.797 & $1.05(0.97-1.13)$ & 0.203 & $1.09(0.95-1.25)$ & 0.231 \\
\hline \multicolumn{9}{|l|}{ Albumin } \\
\hline per unit & $0.74(0.59-0.93)$ & 0.011 & $0.45(0.23-0.88)$ & 0.020 & $0.92(0.62-1.35)$ & 0.664 & $0.70(0.50-0.99)$ & 0.043 \\
\hline \multicolumn{9}{|l|}{ Creatinine } \\
\hline per unit & $1.16(1.00-1.36)$ & 0.057 & $1.35(1.09-1.68)$ & 0.007 & $1.20(0.68-2.13)$ & 0.528 & $1.06(0.82-1.38)$ & 0.641 \\
\hline \multicolumn{9}{|l|}{ CP score } \\
\hline per unit & $1.08(0.99-1.18)$ & 0.089 & $1.13(0.90-1.41)$ & 0.307 & $1.04(0.88-1.23)$ & 0.638 & $1.10(0.87-1.41)$ & 0.415 \\
\hline \multicolumn{9}{|l|}{ MELD score } \\
\hline per unit & $1.05(1.01-1.09)$ & 0.017 & $1.04(0.96-1.13)$ & 0.344 & $1.06(1.00-1.13)$ & 0.056 & $1.02(0.95-1.09)$ & 0.632 \\
\hline
\end{tabular}

The indication NA concerns associations in which no patient or small sample size met the examined criteria and thus the association between these variables could not be evaluated by means of regression

HR, hazard ratio; CI, confidence interval; HCC, hepatocellular carcinoma; CP, Child-Pugh; PVT, portal vein thrombosis; Plt, platelets; PT, prothrombin time; INR, international normalized ratio; MELD, model for end-stage liver disease 